\title{
BRASÍLIA, LONGA DURAÇÃO
}

Marta Bogéa

${ }^{1}$ Agradeço a Bruna Neiva a oportunidade dessa estadia, junto a ela, Gê Orthof, Marilia Panitz, Valéria Cabral, Letícia Garcia a vivência e o acolhimento generosos com que compartilharam tempo e memórias nos dias em que estive lá. A Moacir dos Anjos, a companhia de sempre, no desafio de juntos delinearmos nossas recorrências em inéditas paisagens.
Figura oı - Cao Guimarães, Sin peso 2007 7'oo", http://www.caoguimaraes.com/obra/sin-peso/.

Figura 02 - Foto da autora: afiador no caminho entre a Caixa Cultural e Restaurante. 2019. (página oposta

\section{TENDAS}

Uma balburdia de vozes contradiz a imagem abstrata e colorida que se apresenta na tela do monitor. Um único elemento unifica som e imagem: o vento, com seu ruído sintonizado com o movimento das lonas. A paisagem sonora do curta Sin peso (2007), de Cao Guimarães, se contrapõe à câmara que mostra apenas e, por todo o tempo, lonas coloridas. À medida que damos conta do vento, e o identificamos como o mesmo, no som e na imagem, pode-se reconhecer que as lonas é que abrigam aquelas vozes. É assim que se vai adentrando a atmosfera tão conhecida dos mercados de rua, nesse caso, na cidade do México, no enquadramento proposto por Guimarães.

Rememorei essa imagem, som e cor, ao atravessar o miolo de quadra entre a Caixa Cultural Brasília em direção ao Comércio Local Sul, quando pela primeira vez me defrontei com as "entranhas” de Brasília. Já tinha estado na cidade outras tantas vezes, entretanto em atividades formais, circulando pelas ruas principais, sempre dentro de automóveis, entre o Setor Hoteleiro e as instituições que me traziam à cidade. Dessa vez, pela primeira vez fui pedestre em Brasília em um cotidiano de montagem que me permitiu, ainda que por poucos dias, adentrar a cidade ${ }^{1}$.

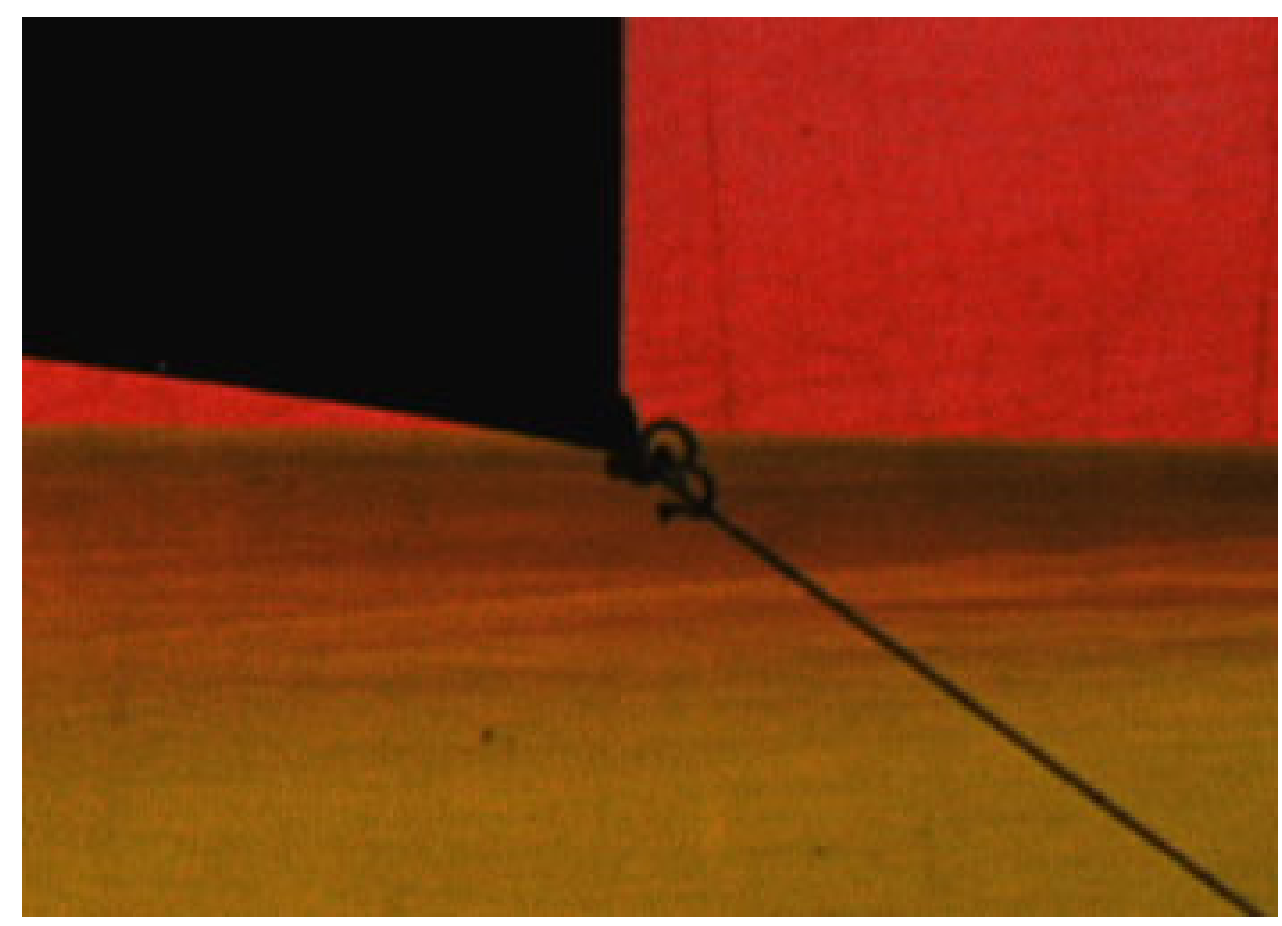




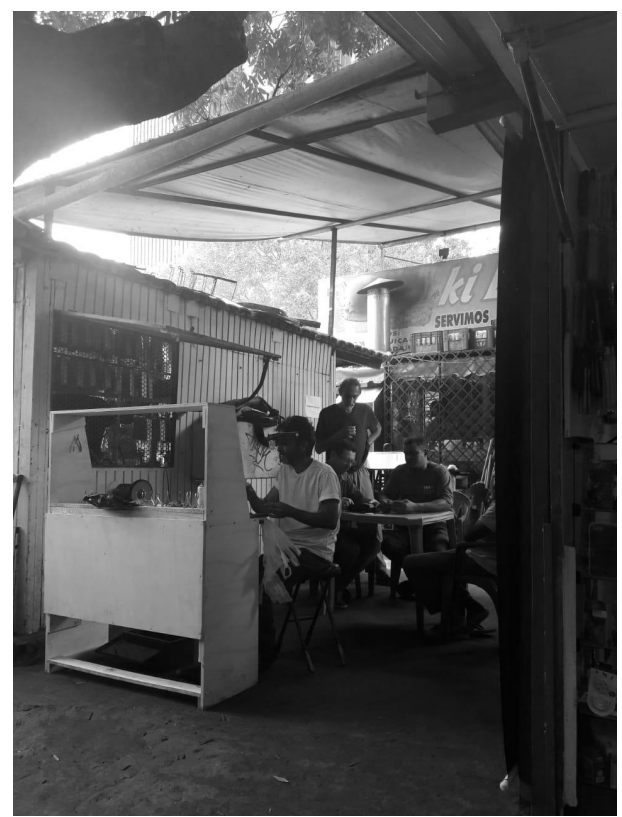

"Bolo, salgado, tapioca, misto quente", indica uma vendinha coberta com toldo colorido como uma tenda; ao lado, um simpático senhor afia facas e alicates. Na passagem de miolo de quadra se avizinham a Frutaria do Wilson, a lojinha de aplicativos para celular Celular e Cia, o Fast Açai SBS. A intrigante experiência ocorrida ao atravessar entre a Caixa Cultural e o restaurante formal revelou o atalho como uma "picada". Retornar ao local através da visão aérea do googlemaps evidenciou que, curiosamente, os endereços das tendas são registrados como dado formal na navegação virtual. Vistos de cima, essas precárias ocupações têm a mesma aparência dos improvisados "puxadinhos" feitos nos fundos das lojas formais.

Coisas de Brasil! Quem diria, também ocorrem dentro do Plano Piloto de
Brasília. Mas, é importante dizer, desde que se possa adentrar suas entranhas!

Os pequenos comércios, de aspecto temporário, entretanto, se instalam por longa duração ${ }^{2}$. Fazem parte da mesma Brasília flagrada por Cao Guimarães em 2011 quando convidado a participar da Bienal "Shenzhen \& Hong Kong Bi-City Biennale of Urbanism $\backslash A r-$ chitecture". Guimarães foi desafiado a filmar a cidade planejada na perspectiva de reconhecer "quando uma cidade vira cidade”, segundo ele ${ }^{3}$, a partir da questão proposta por Terence Riley e equipe, curador-geral da mostra para integrar o núcleo sugestivamente intitulado "and then it became a city" ${ }^{\text {. }}$

O filme começa com imagens diáfanas, enquadramentos dos brancos planos acompanhados pelo texto de Clarice Lispector. É então atravessada por sua corriqueira cotidianidade - que vai revelar inesperadas: charretes, filas de gente alinhada na sombra de um poste, os valentes ambulantes enfrentando o vento, dentre outras imagens que apresentam uma outra Brasília, tão distinta das habituais imagens de seus edifícios emblemáticos, aqui sempre de passagem, sempre nas bordas dos enquadramentos.

A Brasília de Guimarães é um comovente retrato. Nos 13'35" em que acontece revela que há coisas que persistem, qualificadamente em convívio próximo com as tão conhecidas gambiarras ${ }^{5}$ brasileiras com as quais nós nos propomos a transformamos em possibilidade aquilo que a princípio é pura precariedade. Não pelo elogio banal à precariedade, mas pela
2 No Brasil, como sabemos, construções designadas como temporárias perduram obstinadamente mesmo quando tudo indica que seriam em pouco tempo desmontadas. Uma situação que ocorre também dentro dos campos formais, vale lembrar a Sede Transitória para Prefeitura de Salvador de João Filgueiras Lima, construída em 12 dias (1986) amparada pela indicação de que seria transitória e que perdura até hoje, 33 anos depois!

${ }^{3}$ Em diálogo com a autora durante montagem da exposição Território de Contato. Sobre a exposição ver: BOGÉA, Marta e GUERRA, Abílio. "Algo muito humano além de belo, Exposição Território de Contato, módulo 1: Cao Guimarães e Brasil Arquitetura" 144.00 exposição, ano 12, maio 2012. Disponível em http://www.vitruvius.com.br/revistas/read/arquitextos/12.144/4365.

${ }^{4} \mathrm{O}$ núcleo apresentou cinco cidades projetadas retratadas por cinco cineastas selecionados, eram elas: Shenzhen, China; Las Vegas, USA; Almere, The Netherlands, Gaborone, Botswana; Brasilia, Brazil; e Chandigarh, India. Ver a esse respeito: https://www.archdaily.com/176375/ shenzhen-hong-kong-bi-city-biennale-of-urbanism-and-architecture.

5 Gambiarras é uma das conhecidas séries de Cao Guimarães que coleciona estratégias precárias de sobrevivência das mais divertidas como, por exemplo, o pequeno dado que pesa sobre a agulha permitindo a vitrola voltar tocar, ou, dentre uma das mais poéticas, um singelo músico de banda em Ouro Preto prega com pregador de roupa a partitura nas costas do músico que segue em sua frente na procissão musical. Ver http://www. caoguimaraes.com/foto/gambiarras/. 
criteriosa atenção aos que podem enfrentar com galhardia a imprevisibilidade necessária para viver na precária condição de vida ocorrida nos países subdesenvolvidos. O filme finaliza quando caí o dia, em imagens inebriantes da rodoviária, suas luzes cintilantes, sua inquieta e massiva frequentação, momento intrigante no qual a cidade proposta, imaginada, parece coincidir com a cidade de fato.

$\mathrm{Na}$ descoberta naturalizada de tantas lonas, um outro fotógrafo se insinua, remetendo-nos a sua época ainda em construção: Marcel Gautherot e as surpreendentes fotografias da construção da cidade apresenta por ele em duas chaves: a monumentalidade das majestosas construções no Plano Piloto e a precariedade dos abrigos na Sacolândia. São já bastante conhecidas essas imagens produzidas por Gautherot - as das formas icônicas ganhando presença no plano piloto e as da Sacolândia, que não teve publicação àquela época.

Gautherot foi fotógrafo oficial de Brasília, parceiro importante de vários arquitetos na documentação de projetos arquitetônico, paisagísticos e urbanísticos da modernidade. Ao mesmo tempo, parceiro de Pierre Verger, foi colaborador no lia, fotograma do filme. http://www. caoguimaraes.com/obra/brasilia/.

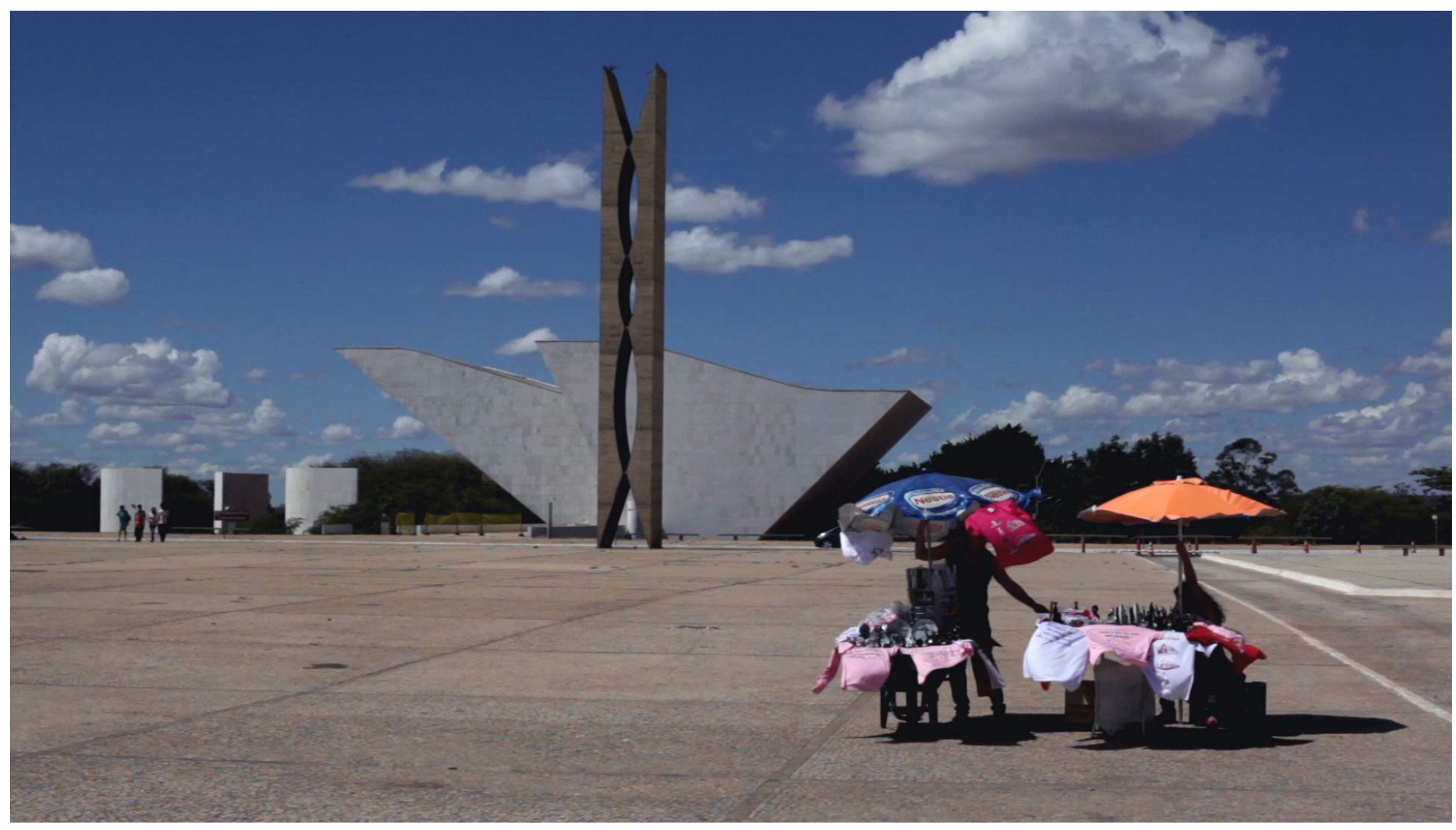



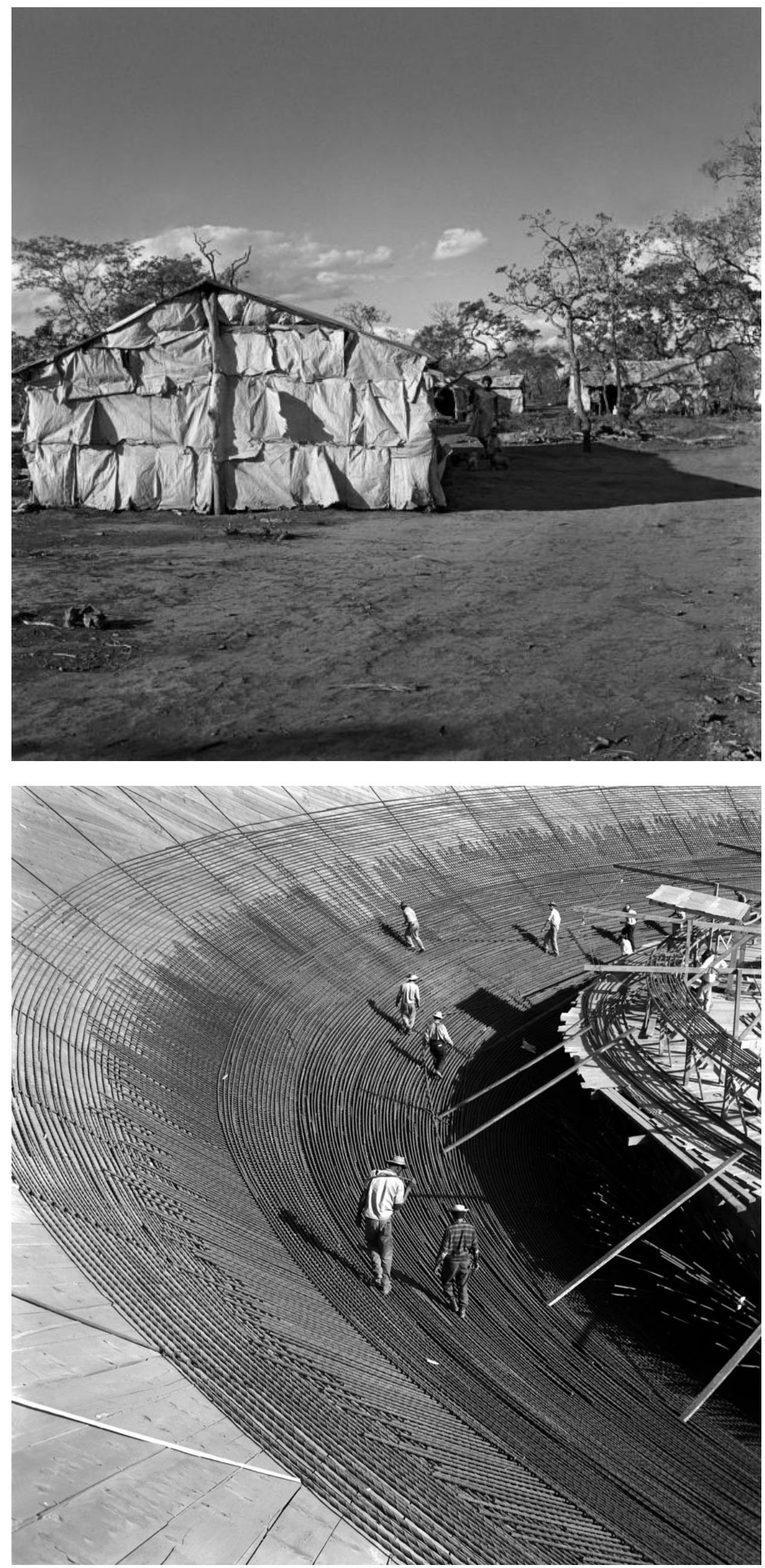

Figura 04 - Moradias na Sacolândia, arredores de Brasília, 1958, Marcel Gautherot. (TITAN e BURGI: 2016, p. 195).

Figura 05 - Palácio do Congresso Nacional em construção, Brasília Fotografia Marcel Gautherot. (TITAN e BURGI: 2016, p. 203). 
Museu do Homem em Paris durante a década de 30. Soube como poucos fotografar as paisagens e suas gentes, retratos tanto de lá quanto de cá. Revelou que a cidade de lonas esteve presente sempre em Brasília, entretanto, na época de sua construção ainda constituíam aparentemente dois territórios. Visto agora os dois territórios parecem fundirem-se em um só, e a "Sacolândia" parece brotar por dentro e a partir do concreto.

Milton Santos já tinha apontado essa ambiguidade desde muito cedo. No texto apresentado em 1964, "Brasília e o subdesenvolvimento brasileiro", declara:

\footnotetext{
"Vontade criadora e subdesenvolvimento do país são, pois, os termos que se afrontamna realização efetiva de Brasília. É da sua confrontação que a cidade retira os elementos de sua definição atual." (Em: KATINSKY e XAVIER (Orgs.): 2012, p. 126).
}

O que entretanto enternece é que essa dupla condição, uma forjada no desejo de superação e outra na continuidade de uma condição social tão frágil moldou Brasília desde sua construção. E o que em 1964 eram elementos de sua definição, em 2019 também ainda o são.

Se acompanhamos Bonesio, essa dupla condição, ao perdurar em longa duração, vai definir Brasília, cidade artificial em um país desumanamente desigual:

"O lugar não é, com efeito, um dado exclusivamente natural, mas uma “invenção" que adquire valor identi- tário e qualidade expressiva apenas no contexto temporal de longa duração" (BONESIO, 2012: p. 209).

E dentro da longa duração de Brasília um de seus inesquecíveis episódios será seu isolamento durante o Golpe Militar, passados apenas quatro anos de sua construção. No memorável texto de Lina Bo Bardi "Em defesa de Brasília" publicado em 1964 em resposta ao editorial da revista milanesa L'Architettura - Cronache e Storia, n.109 ao acusar Brasília de "retórica", "kafkaniana", "antidemocrática" os editores a chamam de "sinistra cidade dos funcionários públicos, artificialmente vestida pelos ornamentos estruturalísticos de Niemeyer". Lina apaixonadamente e generosamente retruca em defesa de Brasília, declara que "A lua é uma terra como qualquer outra se Lunar for Brasilia"6, lembra que "Kafka é um homem", reconhece a "fragilidade dialética de Brasília”, ao reconhecer que

“é pobre, é lunar, é

deseperadamente miserável, mas é a realidade de um país, e não se pode julgar Brasília, que representa um impulso de libertação de um grande país, segundo um esquema preestabelecido e acadêmico culturalmente formalista." (emXAVIER e KATINSKY (orgs): 2012, p. 136).

O episódio que denigre a cidade culpabilizando os artefatos pelas ações dos homens está longe de ser singular, têm sido recorrentes as tentativas em apontar o traçado urbano-arquitetônico como “responsável” sobre essas e outras mazelas 
político-sociais. Diante deles, parece oportuno retomar o questionamento de Bo Bardi,

"Porque o juízo formalista prevalece sobre a avaliação justa, histórica e real, do esforço de uma humanidade que procura o seu caminho no mundo desencantado da realidade de hoje? Porque o juízo formalista prevalece sobre a 'solidariedade' política e moral"? (id. Ibidem)

Diante desse "apelo" os editores publicam o texto da arquiteta, reiteram sua divergência sobre o valor de Brasília entretanto, declaram: "Mas, se se trata de combater os generais, estamos, nos também, prontos para defendê-la"

É preciso reconhecer que o projeto sozinho não pode resolver problemas sociais, assim como tampouco é possível acatar o simplismo oposto de achar que um projeto pode ser a causa de todas os desarranjos sociais, como foi também, singelamente, e tão bem descrito por Josimar Melo, em um lúcido texto de jornal ${ }^{7}$. Coisas corriqueiras que aqui no contexto desse despretencioso ensaio interessa tratar.

Dentre as pequenas coisas, resta saber se o Brasil merece Brasilia, que tão bem encarna um tempo no qual o país delirantemente utópico ousou se imaginar um país moderno. Miragem de uma época em que "o sonho Brasil se vendia em qualquer padaria” como tão bem recordou Claudio Leal - ao se despedir de João Gilberto, no artigo de jornal intitulado "Chega de Saudade" - sonho capaz de produzir desastres mas também de evitar tantos outros. Melancólica e necessária lembrança diante de um atual Brasil distópico.

\section{DA MIRAGEM À VIDA NA CIDADE}

Brasília foi inaugurada em 21 de abril de 1960, no mesmo dia em que Juscelino Kubitschek fechava seu gabinete no Palácio do Catete, até então sede da Presidência da República no Rio de Janeiro. Tem portanto no momento de escritura desse texto menos de 60 anos!

Como existência material, ao compará-la a outras cidades, existe em curtíssima duração. Mas, ainda que se mantenham poucos os anos, Brasília existe desde o momento em que foi pela primeira vez sonhada. E, entre os vários

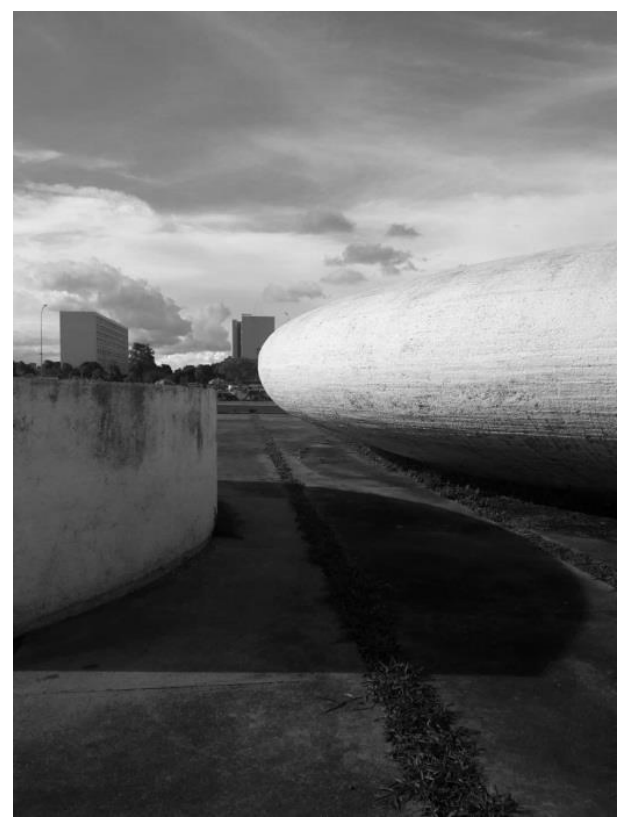

7 “Será mesmo que vizinhos da Casa de Porco preferem 'mercadinho mambembe'?" ilustrada terça-feira 9 de julho de 2019. Josimar Melo é crítico gastronômico, revela nesse texto seu tempo de estudante na Faculdade de Arquitetura da USP, lucidamente sabe distinguir a potência da arquitetura e do urbanismo da totalidade social com que tantas vezes são equivocadamente simplesmente alinhadas. Reconhecendo, é claro, que os artefatos realizados pelos homens materializam também suas crenças e valores, difícil é acreditar que a arquitetura, assim como qualquer outra arte, teria completa autonomia frente aos valores da sociedade que a engendra.

${ }^{8}$ Folha de São Paulo, segunda-feira, 8 de julho de 2019. A chamada logo abaixo do título diz: "Morte de João Gilberto, que será velado hoje no Rio, encerra a utopia de um país do futuro, o delírio da construção de Brasília, do cinema novo e do neoconcretismo sepultado de vez."
Figura 06 - Fotografia da autora em visita a Brasília, Catedral de Brasília, exterior, batistério. Brasília em sua face lunar. 2019. 
Figura 07 - Família de Traba-

Ihadores. Fotografia Marcel

Gautherot, Brasília 1959. (TITAN

e BURGI: 2016, p. 199).

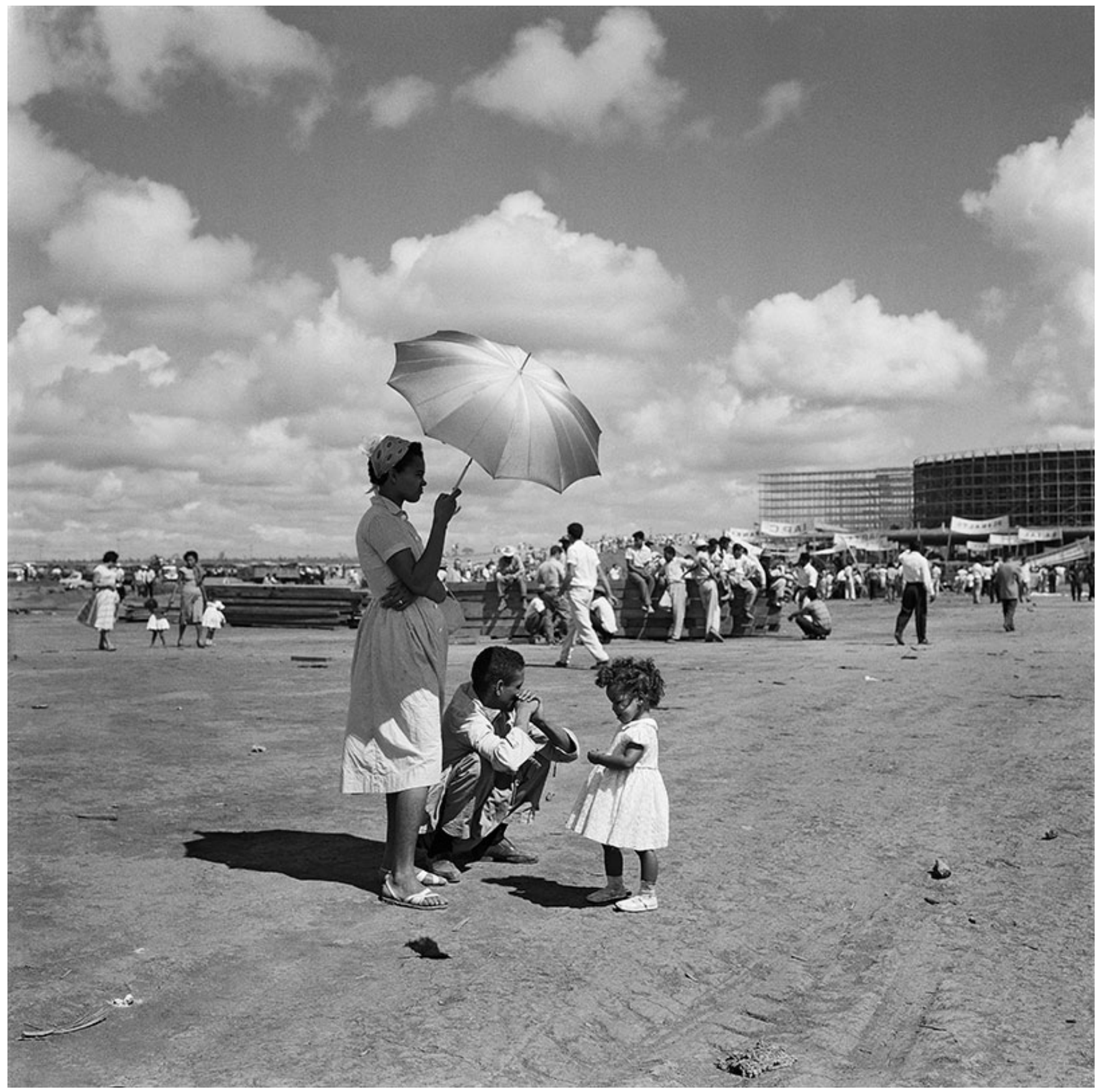


modos com que se vislumbrou a capital do Brasil no interior vale reconhecer alguns momentos muito específicos9.

Os primeiros registro da intenção de transferir a capital do Brasil para o interior do país datam desde meados do século dezessete, com o Brasil ainda colônia. Se dentre eles considerarmos os primeiros mapas com essa intenção Brasília foi inicialmente sonhada em 1749 e teria 270 anos!

A futura capital do Brasil foi nomeada como Brasília em panfleto anônimo em 1822. Se o nome da coisa confere sua primeira existência Brasília teria 197 anos!

A área definida para sua implantação, um quadrilátero de 14.400 quilômetros quadrados, situado na região centro-oeste, resulta da investigação ocorrida pela Comissão Exploradora do Planalto Central do Brasil liderada por Luís Cruz. Conhecida como Quadrilátero Cruz, a área foi apresentada em 1894, com o nome de Vera Cruz. A 7 de setembro de 1922, no contexto das comemorações do centenário da independência uma caravana com um pequeno número de pessoas assentou a pedra fundamental, a poucos quilômetros de onde Brasília viria a ser de fato erigida. Se deve-se considerar esse gesto como a sua primeira demarcação, Brasília teria então 97 anos!

A partir de 1954 os planos aceleram, com a Comissão de Localização da Nova Capital Federal presidida pelo marechal José Pessoa Cavalcante de Albuquerque, nomeado pelo então presidente da república Café Filho, delimitada a área do futuro Distrito Federal e a exata escolha do

local onde hoje se ergue Brasília. O plano

sob essa direção tinha ares conservadores, desde o nome Vera Cruz, sob signo da Cruz de Cristo nossa primeira identidade passando por nomear ruas e avenidas como "independência", "bandeirante", etc. Diferente das atuais siglas alfanuméricas designadas como se sabe W3, SQS, SCS etc. A mudança de imaginário talvez seja o que melhor revela a certeza que fez com que Brasília nascesse moderna, ponto zero de uma certa paisagem, gesto inaugural, imaginário derivado de Juscelino Kubitschek. Sob sua presidência será elaborado o Concurso do Plano Piloto, publicado no Diário Oficial no dia 30 de setembro de 1956. Se o registro do concurso for seu marco, a cidade na feição com se construiu teria 63 anos!

$\mathrm{Na}$ perspectiva do tempo dos lugares - seja por seus 59 anos de existência material, ou por seus 270 anos, desde sua primeira "miragem" - Brasília ainda está se constituindo como lugar, se acompanhamos a definição de Luisa Bonesio, para quem

\section{“O lugar não é, com efeito, um dado exclusivamente natural, mas uma "invenção" que adquire valor identitá- rio e qualidade expressiva apenas no contexto temporal de longa duração" (em SERRÃO, 2012, p. 209).}

$\mathrm{Na}$ sua breve história, Brasília é cheia de intrigantes excessos. Tornou-se Patrimônio Mundial pela UNESCO em dezembro de 1987 , com apenas 30 anos, ou seja, antes mesmo de ter história, Brasília se tornou Histórica!
${ }^{9}$ Ver a esse respeito Sylvia Ficher et al, "Brasilia uma história de planejamento". Em: RODRIGUES et al (orgs.) Brasília 1956>2006, de la fundación de una capital, al capital de la ciudad. Lleida: Milenio, 2006, pp. 55-97. Agradeço a Sylvia Ficher a generosidade do diálogo, e o envio do artigo acima mencionado a partir do resumo deste ensaio. 
Único bem contemporâneo a merecer essa distinção, Brasília é também a detentora da maior área tombada do mundo, 112,25 km². Esse traço a partir do qual a cidade terá que se constituir negociando com sua imagem e o desejo de sua manutenção, faz com que sua artificiosidade passe a integrá-la como traço no tempo. E aquela referida contradição de origem, a cidade moderna capital de um país subdesenvolvido, sua marca mais evidente.

Pois “(...) a casa vivida é também a casa sonhada, a casa de onde se partiu e a casa onde se vai regressar, a casa de nossos antepassados e a dos nossos filhos, enfim, a casa que o tempo sepulta e que o tempo renova." (JORGE, em SERRÃO: 2012, p. 182)

Figura 08 - Fotografia da autora em visita a Brasília, Igrejinha Nossa Senhora de Fátima. 2019.
Brasília como casa sonhada tem correspondências surpreendentes com a casa projetada e posteriormente com a casa vivida. Uma visita em um fim de tarde de uma sexta feira comum na Superquadra 308 Sul - Quadra Modelo da Construção de Brasília, permitiu-me viver uma paisagem entre edifícios, na continuidade de um jardim, conversavam velhos, fumavam jovens, corriam crianças - parecia cena de filme bucólico de alguma utopia descrita por urbanistas a propor coisas inalcançáveis. $O$ desenho tão veiculado de cidade modelo persiste: o térreo se mantém permeável para abrigar qualquer transeunte diante de um inesperado temporal, vizinhos a confabular sobre a vida; pessoas que vão de lá para cá com a fluidez somente imaginada em áreas habitacionais como miragem para nós que vivemos em cidades com edifícios habitacionais cada vez mais cercados por altos e opacos muros.

Aqui o artifício virou realidade. Podem esbravejar os opositores de Brasília mas indubitavelmente é também por esse espanto que a cidade continua a ser um dos ícones da modernidade ainda hoje tão visitado. Os colchões amontoados na curvatura da igrejinha, a Igreja Nossa Senhora de Fátima, inaugurada em 1958, deixa claro que sim, ainda estamos no Brasil e não em Tiergarten, em Berlim. Por que seria mesmo tão pouco possível desejar esse país?

Surpreende a persistência com que a qualificação dos espaços assegura certos modos de vida, da quadra modelo, e também da rodoviária. Dois distintos lugares, 
um demarcado por um modo de moradia elitizado - mas como não dizer, tão mais elaborado e gentil como urbanidade que os condomínios murados - o outro lugar de chegada da população mais pobre, através do meio de transporte popular.

Se Cao Guimarães ao retratar Brasília não se atém à quadra modelo, não resiste por outro lado a vislumbrar como miragem a buliçosa rodoviária. Campo de centralidade popular que endereçou para o coração da cidade também uma outra vivacidade.

Não à toa, dentre os itens apontados por Lucio Costa como aqueles que o importam principalmente como urbanista da cidade interessa "respeitar e manter as características originais dos dois eixos e de seu cruzamento", em seus termos:

"Manter a plataforma rodoviária como traço de união e ponto de convergência já consolidado do complexo urbano composto pela cidade político-administrativa e pelos improvisados assentamentos satélites." 10

No mesmo documento, no item 5:

"A manutenção do conceito de superquadra como espaço residencial aberto ao público, em contraposição ao de condomínio privativo fechado; da entrada única; do enquadramento arborizado; do gabarito uniforme de seis pavimentos sobre pilotis livres, como os blocos soltos do chão."

Em um raro lugar no mundo onde os pilotis se mantêm como imaginados, lugar de passagem, aberto a usos imprevistos e não apenas zonas garagem ou térreo gradeado.

Lucio Costa com a mesma lúcida exatidão com que delineou o plano

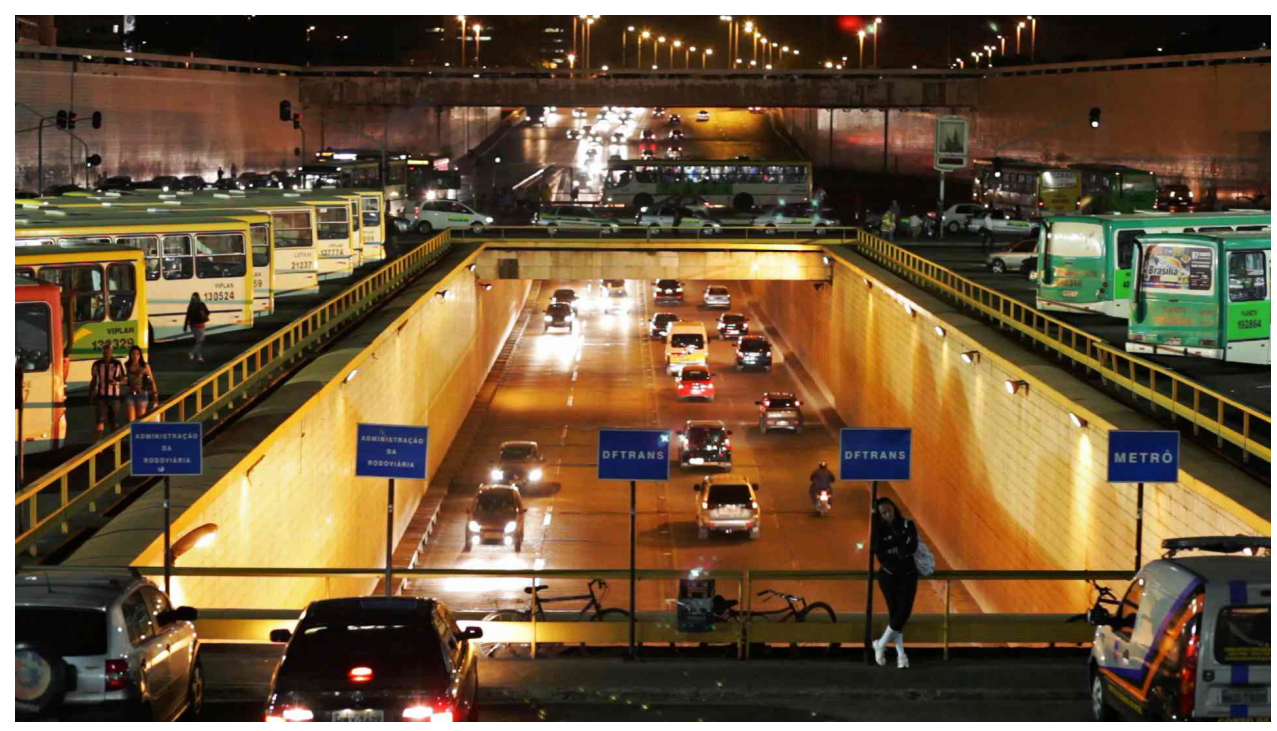

10 Diretrizes para a preservação da integralidade do plano piloto, em carta escrita em janeiro de 1990 (p.292).

Figura 09 - Cao Guimarães Brasília, fotograma do filme. http:// www.caoguimaraes.com/obra/ brasilia/ 


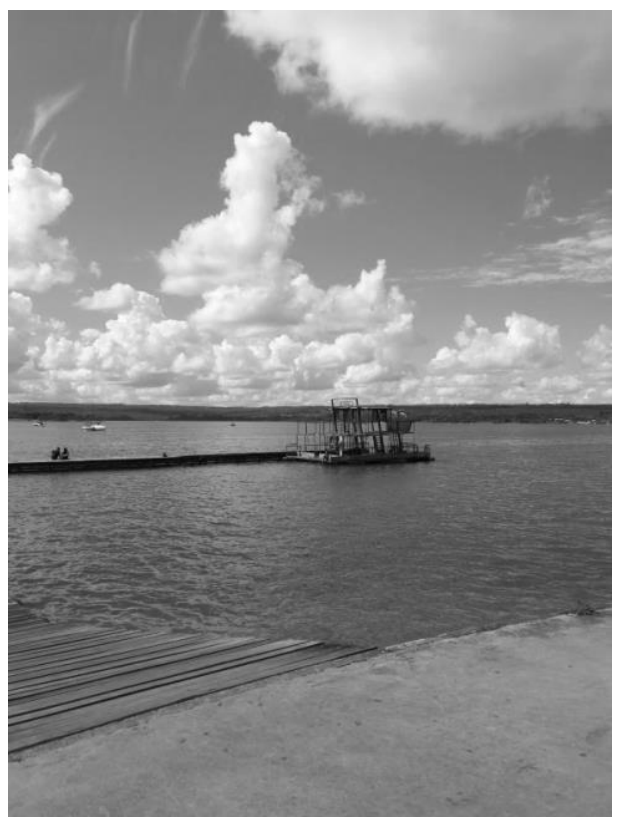

margem do Lago Paranoá. Resto estrutural de uma balsa, 2019. piloto deixa assim registrado em duas páginas, se tanto, suas indicações para preservação da cidade. Conclui com a seguinte frase:

"Como se vê, trata-se, em suma, de respeitar Brasília. De complementar com sensibilidade e lucidez o que ainda lhe falta, preservando o que de válido sobreviveu.

A cidade, que primeiro viveu dentro da minha cabeça, se soltou, já não me pertence pertence ao Brasil." (p. 293).

No que merece rememorar fica atenção àquilo que permanece como qualidade, o que persiste, e que na materialidade dos fatos urbano arquitetônicos abrigam modos de viver capazes de qualificar e dignificar um viver lá!

O lago revelou-se um manancial qualificador do espaço corriqueiro, atenua o tempo seco do lugar, convida a todo tipo de esporte aquático, perdura como território de água desejável. Desde os primeiros estudos da região, ao se definirem o local da implantação da nova cidade. Pois em 1955 após tantos estudos e levantamentos optou-se pelo exato sítio que o botânico Auguste Glaziou escolherá em 1893, descrito por ele em carta endereçada a Cruls nos seguintes termos:

"Enfim, de jornada em jornada, estudando tudo, cheguei a um vastíssimo vale banhado pelos rios Torto, Gama, Vicente Pires, Riacho Fundo, Bananal e outros; impressionou-me muitíssimo a calma severa e majestosa desse vale...Entre dois chapadões conhecidos na localidade pelos nomes de Gama e Paranoá, existe imensa planície em parte sujeita a ser coberta pelas águas da estação chuvosa; outrora era um lago devido à junção de difeentes curos de água, formando o rio Paranoá (...) (em SILVA apud Ficher et al: 2006, p. 3).

Essa coincidência, incrível exemplo de amnésia histórica, nos termos de Sylvia Ficher, Geraldo Batista, Francisco Leitão e Andrey Schlee, entre as primeiras incursões oficiais na busca de um sítio de localização, na área definida para o projeto no concurso e, que resulta hoje em importante identidade da paisagem urbana, a extensa área, e a presença do lago.

Se, "De facto, na cidade coexistem as heranças e os seus herdeiros: uma 
cidade narra a História do seu passado e do seu presente. E, a partir daí, constrói posteriormente, o seu futuro. Aquilo que nela acontece decorre daquilo que nela antes aconteceu". (JORGE, em SERRÃO: 2012, p. 180).

O gesto de registro dessas memórias dispersas são o contributo necessário para constituir a desejável identidade da cidade. Trabalho criterioso que vem sendo constituído por aqueles que vêm se atendo à análise de Brasília.

Esse ensaio, elaborado por um eventual visitante, comemora a tradição em Brasília, jovem cidade moderna, que nasceu dentro de uma visão de mundo afeita a fatos inéditos e que precisa se constituir no tempo sobrevindo a esse legado, na medida em que, apesar de moderna, é prenhe de renovadas tradições. Algumas diretamente endereçadas a ela, outras, apenas porque transportadas como memórias acopladas nas vidas de tantos que a dotaram como sua cidade para viver.

Das memórias que já decorrem de lá, durante a rápida estadia em que pude lá ficar, mantiveram-se comigo a imagem do ônibus "brotando no horizonte da paisagem" aguardado seu contorno e de quem sairá de lá pelas crianças, hoje adultos, que faziam da rodoviária passeio corriqueiro; a lembrança do ponto de encontro sob a laje de um certo edifício para combinar quem acompanhará as brincadeira das crianças; a ida casual ao Beirute, que "sempre" esteve lá (inaugurado em 1966, de acordo com sua placa) e me perceber sob uma das regrada e regular; a carcaça metálica de uma antiga balsa servindo de estrutura para tomar sol e trampolim no vastíssimo lago Paranoá; o sussurro ao "pé da parede curva" na Catedral de Brasília, de onde se podem segredar fatos a uma distância impossível de ser vencida aos sussurros.

Pequenas estórias, que talvez não interessem a ninguém, entretanto, como observou a moradora da Croix-Rousse: “(...) é pessoal, isto não interessa a ninguém, mas enfim é isso que faz o espírito do bairro." e diante da frase, esclareceu Michel de Certeau:

\section{"Só há lugar quando frequentado por espíritos múltiplos, ali escondidos em silêncio, e que se pode evocar ou não. Só se pode morar num lugar assim povoado de lembranças". (CERTEAU: 1994, p. 189)}

Brasília em longa duração revela-se uma cidade que vem acumulando memórias contraditórias, divergentes, espetaculares mas também corriqueiras. Todas elas a constituir sua complexa paisagem, que insistentemente tem sido apresentada por suas icônicas imagens, mas que começa a contar também com uma outra coleção tão humanamente banal de registro de suas paisagens.

A cidade construída em 3 anos, que materializa apenas 59 anos, conta já com memórias que figuram a pelo menos a 270 anos! Liberar as representações da cidade de um traço unívoco, de um 
11 Nos primeiros começos de Brasília. Publicado em 1970, em: XAVIER e KATINSKY (orgs). Brasília - antologia crítica. São Paulo: Cosac Naify, 2012. pp. 179-182.Versão ampliada com post scriptum -2019 , acrescido ao texto homônimo apresentado no ARQUIMEMÓRIA 5, Salvador / 2017. imaginário sempre moderno, inédito, é tarefa para cada um de nós aptos a reconhecer Brasília. Que possamos re-apresentá-la, como fez Cao Guimarães, ou mesmo alinharmo-nos com Clarice Lispector ${ }^{11}$ quando em 1970, já nos primeiros começos da cidade, definiu-a como a imagem de sua insônia, "nem bonita nem feia”, vivida! Assim, quem sabe, poderemos melhor usufruir Brasília, entre sonhos, miragens e banalidades.

\section{REFERÊNCIAS BIBLIOGRÁFICAS}

BO BARDI, Lina. Em defesa de Brasília. Em: XAVIER, Alberto e KATINSKY, Julio (orgs). Brasilia - antologia crítica. São Paulo: Cosac Naify, 2012. pp. 135-136.

BONESIO, Luisa. Habitar a Terra e reconhecer-se nos lugares. Em: SERRÃO, Adriana Verísssimo (coord.). Filosofia e Arquitetura da Paisagem: Um Manual. Lisboa: Centro de Filosofia da Universidade de Lisboa, 2012. pp 203-210.

CERTEAU, Michel de. A invenção do cotidiano. 1. Artes de fazer. Petropolis: Vozes, 1994.

COSTA, Lucia. Diretrizes para a preservação da integridade do Plano Piloto. Em: XAVIER, Alberto e KATINSKY, Julio (orgs). Brasilia - antologia crítica. São Paulo: Cosac Naify, 2012. pp. 292-293.

FICHER, Sylvia; BATISTA, Geraldo, LEITÃO, Francisco; SCHLEE, Andrey. Brasília: uma história de planejamento. Em: RODRIGUEZ, Eduard e FUGUEIRA, Cibele Vieira (orgs) Brasília 1956-2006, de la fundación de una ciudad, al capital de la ciudad. Lleida: Milenio, 2006. pp. 55-97.

GUIMARÃES, Cao. Brasilia. Filme 13'35”, digital HD. 2011. acesso restrito. http://www. caoguimaraes.com/obra/brasilia/.

GUIMARÃES, Cao. Sin Peso. Filme 7'00”, DVD. 2007. acesso restrito. http://www.caoguimaraes.com/obra/sin-peso/.

JORGE GORJÃO, José Duarte. O tempo da cidade. Em: SERRÃO, Adriana Verísssimo (coord.) Filosofia e Arquitetura da Paisagem: Intervençôes. Lisboa: Centro de Filosofia da Universidade de Lisboa, 2012. pp 179-185.

LISPECTOR, Clarice. Nos primeiros começos de Brasília. Em: XAVIER e KATINSKY (orgs). Brasilia - antologia crítica. São Paulo: Cosac Naify, 2012. pp. 179-182.

SANTOS, Milton. Brasília e o subdesenvolvimento brasileiro. Em: XAVIER, Alberto e KATINSKY, Julio (orgs). Brasilia - antologia crítica. São Paulo: Cosac Naify, 2012. pp. 125-134. 
TITAN Jr., Samuel e BURGI, Sergio (orgs.). Marcel Gautherot fotografias. São Paulo: IMS, 2016.

Shenzen Hong-Kong bi-city biennele of urbanism architecture.

Em:http://www.biennialfoundation.org/biennials/shenzhen-hong-kong-bi-city-biennale-of-urbanism-architecture/ e https:/www.archdaily.com/176375/shenzhen-hong-kong-bi-city-biennale-of-urbanism-and-architecture. Acesso em julho de 2019.

Marta BogÉa - Arquiteta Urbanista (UFES 1989), Livre-docente (FAUUSP 2018), Bolsista CNPq Produtividade em pesquisa 2. Professora no Departamento de Projeto, áreas de concentração Projeto, Espaço e Cultura, Projeto de Arquitetura da Faculdade de Arquitetura e Urbanismo da Universidade de São Paulo. mbogea@usp.br. 